\title{
Patient Power Revolution in Multiple Sclerosis: Navigating the New Frontier
}

\author{
David Yeandle · Peter Rieckmann • Gavin Giovannoni • \\ Nektaria Alexandri · Dawn Langdon (1)
}

Received: October 30, 2018 / Published online: November 9, 2018

(C) The Author(s) 2018

\begin{abstract}
A debate on shared decision making in multiple sclerosis (MS) was led by a patient advocate and leading neurologists from the MS in the 21st Century Steering Group. Key themes and salient points which emerged from the debate and audience discussions are reported in this article. Arguments against shared decision making included the fact that physicians study and practice for years to reach their level of expertise, and that the level of understanding required to make these decisions may not be possible to communicate to patients within time-limited consultations. Furthermore, unreliable online information, information overload or information with marketing bias may also
\end{abstract}

Enhanced digital features To view enhanced digital features for this article go to https://doi.org/10.6084/ m9.figshare.7285418.

D. Yeandle

Member of the MS in the 21st Century Steering

Group, Southampton, UK

P. Rieckmann

Medical Park, Loipl, Bischofswiesen, Germany

G. Giovannoni

Blizard Institute, Barts and the London School of

Medicine and Dentistry, London, UK

N. Alexandri

Global Medical Affairs, Neurology and

Immunology, Merck KGaA, Darmstadt, Germany

D. Langdon $(\bowtie)$

Royal Holloway, University of London, London, UK

e-mail: d.langdon@rhul.ac.uk cloud patients' judgements. Arguments for patient engagement focussed on how ownership of decisions can lead to improved adherence and outcomes, and a strengthening of the physician-patient relationship. Shared decision making requires educating patients to make informed decisions and to understand the risks and consequences of their choices. However, shared decision making may not be the correct option for every patient, and the level of involvement must be driven by the patient. To support patients' engagement and promote responsible management of their condition, physicians need to (1) foster and maintain a positive, ongoing relationship with their patients, and (2) provide patients with timely, accurate, and understandable information. There was broad agreement that the patient voice should be heard more in discussions around the future of MS care. MS in the 21st Century offers a model for patient involvement in partnership with MS healthcare specialists, and the steering group is currently considering these issues and developing tools and solutions to enhance patient-physician communication and relationships.

Funding Merck KGaA, Darmstadt, Germany.

Keywords: Communication; Education; Multiple sclerosis; MS in the 21st Century; Patient engagement; Patient voice; Shared decision making 


\section{INTRODUCTION}

Like many aspects of medicine, care in multiple sclerosis (MS) has historically been paternalistic in nature, with healthcare professionals (HCPs) typically making treatment decisions independently of patient preference. However, there is now a sweeping shift towards increased patient engagement, defined broadly as the 'active involvement of patients in their own care, in order to enhance safety, quality and peoplecentredness of health care service delivery' [1]. Patient engagement is widely considered to be the gold standard for ethical care; this includes giving patients greater ownership of their healthcare through shared decision making and recognition of the patient perspective at all levels, from discussions about individual care through to organisational or national policy $[2,3]$.

With increased recognition of the importance of the patient voice, there are now many initiatives to facilitate and support shared decision making in health (e.g. National Health Service England's commitment to shared decision making, or the Centre for Advancing Health's report Here to Stay: What Health Care Leaders Say About Patient Engagement) [4, 5]. In MS, research has been undertaken to investigate how well patients with MS (pwMS) understand their treatment and how communication between pwMS and HCPs can be improved [6-9].

MS in the 21st Century is an international group of patient advocates and HCPs, collaborating to raise awareness of, and identify solutions to, issues in MS care. Together, the group has developed MS care consensus statements and identified unmet care needs $[9,10]$. As part of their programme of challenging the MS status quo and disseminating their perspective of patient engagement and advocacy, MS in the 21st Century hosted a symposium on 2 December 2017 at the European Charcot Foundation, an influential neurology conference attended by internationally recognised neurologists. Led by a patient advocate and leading neurologists from the MS in the 21st Century Steering Group, the symposium took the form of a debate on the involvement of pwMS in shared decision making.

Although MS in the 21st Century is committed to advancing shared decision making, it was recognised that the need for caution regarding patient engagement must also be considered on ethical and clinical grounds. Treatment requires informed consent; patients may choose not to hear about treatment risks, but information about other aspects of the treatment options should still be discussed if possible. However, not all patients would want the responsibility or complexity of involvement in their treatment or other health decisions [11]. For example, patients with higher disability and more relapses might be more interested in shared decision making, perhaps perceiving that prior treatment decisions have not worked optimally for them [12]. Both sides of the argument were presented in the context of MS.

In line with MS in the 21st Century's philosophy of collaboration and mutual respect between pwMS and HCPs, consultation and drafts of the content and format went through many iterations, informed by all members of the steering group. The debate was chaired by neuropsychologist Dawn Langdon, with neurologists Gavin Giovannoni and Peter Rieckmann presenting opposing views, for and against patient involvement in shared decision making, and patient advocate David Yeandle providing the patient voice. The aim was to elicit contributions from the audience and stimulate discussion among those attending. Here we report the key themes and salient points which emerged from their discussions.

\section{AGAINST PATIENT ENGAGEMENT}

When the movement for greater patient engagement in MS began, only two therapies (interferon beta and glatiramer acetate) were available [10, 13]. However, rapid advances in recent years mean that there are now 17 different therapies available, creating a complex treatment landscape. Physicians study and practice for years, even decades, to develop expertise in their chosen therapy areas; it is unreasonable to expect every patient to fully 
understand the underlying aspects of their condition, the options that are available for its management, and the consequences of their choices in terms of efficacy, mechanisms of action, and potential adverse effects. Sadly, physicians cannot give each patient the time needed to fully explore and educate them on each option prior to embarking upon treatment. Furthermore, patients can be influenced by external sources of information, such as promotional marketing, that physicians may struggle to identify and balance against.

The concerns about overwhelming patients with the amount of information necessary for shared decision making were laid out in a recent paper showing that a paternalistic approach, whereby physicians make choices on behalf of their patients' well-being, has historically been typical for medicine [14]. In many cases, physicians have experienced situations where patients have been overwhelmed by options and information, leading to confusion or anxiety. Often, both parties have found it beneficial for the physician to take the lead in making clinical decisions [14]. However, it is important to note that a paternalistic approach to care is not incompatible with shared decision making; delegating the decision-making to their physician or neurologist is one of the options available to pwMS.

The audience mentioned that patients rarely foresee probable outcomes with the same clarity as an experienced physician. We all tend to be more optimistic about our own health and to prioritise short-term outcomes over longer-term ones. Physicians have a greater level of expertise and objectivity when predicting patient outcomes than pwMS may have for themselves, and it is understandable why many pwMS are reluctant to accept a lifetime of pharmaceutical therapy; these differences in expectations can make shared decision making challenging for both physicians and pwMS.

Ultimately, the responsibility for the patient lies with the physician. It may not always be easy for a physician to make a decision, but they know that, more often than not, they can trust their own judgement and that they accept the responsibility inherent to this decision. Patients do not have years of education and expertise within a therapy area, and giving them the responsibility for treatment decisions and their outcomes may be doing them a disservice when the focus should be on supporting them to manage and live with their condition.

\section{FOR PATIENT ENGAGEMENT}

Greater involvement in disease management has been shown to improve patients' ownership of and commitment to therapy; patient engagement is often referred to as 'the blockbuster drug of the 21st century' [15]. In broad terms, greater patient engagement leads to improved outcomes (measurable in terms of adherence or mortality), reduced healthcare consumption (as measured by diagnostics, referrals, and direct healthcare costs), and improved service quality (measurable through communication, patient health literacy, healthcare staff retention, and HCP-patient relationship satisfaction) [10, 16-21].

If we expect pwMS to adhere to their treatment regimens and appointment schedules, we should also give them some say and agency on how their disease is managed. A key aspect of patient engagement is the recognition that patients are individuals, with different needs, lifestyles, and priorities. By involving patients, care teams can come to decisions which are most appropriate for the individual, taking all of their life circumstances into consideration, not just their disease.

Poor adherence and discontinuation of treatment prevent the effective management of MS, with several real-world studies indicating that within a few years of initiating treatment, about $30 \%$ of pwMS discontinued or were nonadherent to their therapy regimen [22-25]. Patients who do not feel they have a say in clinical decision making, and who lack in-depth understanding and realistic expectations of their care choices, are more likely to be nonadherent or discontinue therapies entirely [26]. Conversely, patients who are involved via shared decision making are more likely to feel a sense of responsibility for the management of their condition, which translates into greater 
satisfaction, better adherence, and improved outcomes [10, 27, 28].

\section{FINDING THE RIGHT BALANCE}

The two positions discussed above are not mutually exclusive. Whilst there is no disputing the expertise that physicians bring to a consultation, when physicians guide treatment decisions, they must, in turn, be guided by the individual patient's expressed best interest. The patient is always the ultimate arbiter, as it is they who decide whether they adhere to the treatment and regularly introduce the drug into their body. However, it is often not optimal to give all of the responsibility to the patient. The audience raised the point that handing patients a leaflet and asking them to come back with their decision is a more dangerous approach than pure paternalism. Truly empowering patients means educating them to make informed decisions, including understanding the risks and consequences of their choices.

Historically, physicians have been the gatekeepers for access to both therapy and disease knowledge. In the age of information technology, the latter role has been severely compromised, sometimes leading to a loss of faith in doctors. While there is a wealth of information available online, unfortunately, not all of it is reliable, and some of it is misleading or even dangerous. Patients with MS can therefore struggle to navigate this sea of information without guidance, and simply leaving them to do so by themselves is unhelpful for patients and their relationship with their HCP [29]. Unsurprisingly, pwMS who better understand their disease and treatment tend to be more engaged and show greater treatment adherence [30].

Scripted education programmes can improve disease knowledge; however, they do less well at enhancing decision making and quality of life [31]. Whilst patient organisations often produce high-quality information which is useful background reading, they cannot know the individual patient's profile and customise information to their particular circumstances. Some pharmaceutical companies offer support programmes to patients on particular medications, but these have not been objectively evaluated. Overall, it seems that individual consultations that are tailored to the individual by the HCP, and which allow exploration of preferences, fears, and priorities, are the most useful.

It was noted that pwMS should be supported to feel comfortable discussing difficult topics. The presence of a family member can be helpful for these discussions, and patients often view their treatment decisions and adherence as activities to be shared with their family support network [32]. The perception of an open dialogue and trust with their physician contributes to patient satisfaction [33]. In order to support patients' engagement and promote their management of their condition, physicians need to (1) foster and maintain a positive, ongoing relationship with their patients, and (2) provide patients with timely, accurate, and understandable information.

However, it is important to remember that information does not equal education, and the ability to make the complexities of medicine comprehensible for patients is an important skill. Physicians must consider not only what they communicate, but also how and when this is done in order to ensure they educate rather than mystify or mislead. Sadly, physicians often have little, if any, formal training in soft skills such as communication and conflict management [10, 34-37]. It was noted that, like most precious things, a trusting relationship between a patient and their physician is difficult to create and develop, but all too easy to damage.

Medicine relies on a clinical evidence base, but it is not a pure science. Much of it is an 'art', informed by an HCP's experience with their patients. Tailoring patients' involvement according to the physician's experience and clinical intuition would be essential in any shared decision-making system. One cannot ignore the fact that more choices make for more complex discussions. Physicians should therefore be able to personalise their approach as appropriate, even if that means restricting the range of choices presented to some patients. Even when decision making is not shared, 
explaining the rationale behind the choices the physician has made can strengthen the relationship with their patient and improve engagement. Inviting comment and discussion may reveal information which may cause the physician to reconsider the optimum choice they have made.

The audience noted that, when shared decision making takes place, physicians must accept that patients will not always ultimately choose the option a physician might have recommended. It is important that a trusting relationship exists, in which both parties can share a dialogue and push back against decisions they disagree with. If a pwMS persists with a choice against their physician's advice, it is important that the physician respects their patient's wishes and continues to provide the best support they can within the constraints of the patient's decision. Within a positive and open relationship, patients have room to return and consult their physician if their chosen option is not meeting their needs. In the context of a chronic disease, the relationship is ongoing and, as the relationship develops, both parties have opportunities to learn from one another. As this experience grows, an open, honest, and mutually respectful relationship can hopefully develop, and patients are then more likely to trust their physician's advice.

Several participants noted that the greatest challenge for patient empowerment and a positive patient-physician relationship is the restriction on physicians' time. Given these constraints, it is important that appointments are used optimally for effective communication. During the debate, participants stressed that, while it is crucial that physicians listen to patients, research indicates that patients are often interrupted after only 23 seconds of speech [38], despite only taking an average of 92 seconds to relay their concerns if allowed to talk without interruption [39], and that this can lead to misunderstandings and assumptions. Physicians must use their clinical skills to support patients who may struggle to make their point, get bogged down in irrelevant information, or have difficulty expressing their message clearly.
Accordingly, it is worth considering how the appointment process could be adjusted to better benefit pwMS. Is a standard duration (e.g. 30 minutes) appropriate for each patient and for every appointment? Could we improve the effectiveness of appointments by creating a loose agenda ahead of time to ensure that nothing is missed, and that both parties can better prepare? Can digital technologies assist patients and physicians ahead of appointments, including helping patients to understand information and share their questions ahead of time? And how can physicians better acknowledge and respond to questions from patients which arise during or after an appointment?

While shared decision making is clearly an important part of patient engagement, its success is reliant on effective patient-physician communication. Research has consistently indicated significant barriers to communication between HCPs and pwMS, with disconnects often present in terms of disease understanding, treatment expectations, and priorities within care $[9,26,40]$. For example, HCPs typically prioritise physical functioning, whereas pwMS place more emphasis on mental health domains [41-44]. Healthcare professionals have been shown to underestimate the impact of MS on their patients' physical and psychological health early in a rehabilitation programme, but less so at the end, suggesting that with improved contact and communication, patients' and HCPs' perceptions of disease impact can align [45].

Similarly, there is considerable evidence to support the view that improved patient-physician communication, patient-centred care, and shared decision making are associated with increased patient satisfaction and empowerment, less decision conflict, less treatment noncompliance, less medical litigation, and a stronger patient-physician alliance $[10,27,46,47]$. Unsurprisingly, patient understanding of the MS disease process enhances medication adherence [30], and those MS patients who feel that their autonomy is supported are more likely to adhere to medication regimens [28].

It is far from clear whether shared decision making is the correct option for every patient, 
every time. It is also important to remember that communication and engagement isn't always a neurologist-led process. Nurses, physiotherapists, occupational therapists, and other members of the healthcare team can be equally, or more, important facilitators of patient communication. It is essential that there is good communication among these different members of the healthcare team and that they are sharing their unique insights with one another. Regardless of how much autonomy and involvement each patient prefers, there should be a clear and shared understanding of the rationale for treatment choices and of the patient's perspective among all those involved in the care of the patient.

It was noted that the MS in the 21st Century Steering Group is considering these issues and that, by studying the existing literature [27], and with the support and feedback of the broader MS community, it is developing tools and solutions to enhance patient-physician communication and relationships.

\section{NAVIGATING THE NEW FRONTIER}

In this debate, the speakers presented different perspectives regarding the extent of patient engagement in shared decision making, providing explanation and reflection on why this might vary for different patients and how it could best be optimised. There was a great deal of lively debate with the audience, with members making many useful contributions. This may have been the first time that many of those attending had heard the value of patient engagement being debated by a patient advocate and HCPs. There was broad agreement that the authentic patient voice needs to be heard more; there should be more presentations on this subject at major conferences and more publications produced in genuine collaboration with patients. MS in the 21st Century offers a model for patient involvement, and this debate demonstrates what can be achieved by inclusion, commitment, planning, and a willingness to address difficult issues. It is hoped that this debate provides reinforcement for the value of well-considered patient centricity in clinical practice. The MS in the 21st Century Steering Group is currently developing communication tools, based on collected survey data, to optimise routine healthcare consultations for pwMS, which will be available in the near future.

\section{ACKNOWLEDGEMENTS}

The members of MS in the 21st Century are as follows: Birgit Bauer, Diego Centonze, Maria Paz Giambastiani, Gavin Giovannoni, Jeremy Hobart, Jürg Kesselring, Dawn Langdon, Sarah Morrow, Jocelyne Nouvet-Gire, Celia OrejaGuevara, Maija Pontaga, Stanca Potra, Peter Rieckmann, Sven Schippling, Jane Shanahan, Christoph Thalheim, Heidi Thompson, Pieter van Galen, Patrick Vermersch, and David Yeandle. We thank the European Charcot Foundation audience members for their contributions to this debate.

Funding. The MS in the 21st Century initiative is financially supported by Merck KGaA, Darmstadt, Germany. The article processing charges were also funded by Merck $\mathrm{KGaA}$, Darmstadt, Germany.

Medical Writing and/or Editorial Assistance. Administrative support and editorial input was provided by Cello Health Communications. Medical writing assistance was provided by Cello Health Communications (Owen Webb, Helen Hammond, and Krishan Kapoor). Administrative support, medical writing assistance, and journal submission fees were funded by Merck KGaA, Darmstadt, Germany.

Authorship. All authors had full access to all of the content within this manuscript and take complete responsibility for the integrity and accuracy of the content. All named authors meet the International Committee of Medical Journal Editors (ICMJE) criteria for authorship for this article, take responsibility for the integrity of the work as a whole, and have given their approval for this version to be published. 
Disclosures. David Yeandle receives honoraria from Merck $\mathrm{KGaA}$ as part of his work on MS in the 21st Century. Peter Rieckmann has received honoraria for lectures from Almirall, Apple Healthcare, Baxter, Bayer, Biogen Idec, Boehringer-Ingelheim, Cerner, Daiichi Sankyo, Genpharm, Genzyme, Medtronic, Merck Serono, Novartis, Pfizer, Roche, Sanofi-Aventis, Siemens AG, and Teva. He has received research grants from Bayer, EMD Serono, Novartis, Teva, the MS Society of Canada, Canadian Institutes of Health Research, Hertie Foundation, Oberfranken-Stiftung, and German Neurology Foundation. He is on an advisory board or steering committee for AbbVie, Bayer, Biogen Idec, Novartis, Merck Serono, Teva, the German Multiple Sclerosis Society, and Canada Drug Review. Gavin Giovannoni is a steering committee member for AbbVie (daclizumab trials) and Biogen Idec (BG12 and daclizumab trials), and has received honoraria for speaking from Canbex Therapeutics. He is a clinical advisor regarding the development of VSN16. He has received consultancy fees for advisory board meetings for GW Pharmaceuticals, and for speaking at the launch of Sativex in Norway. Nektaria Alexandri is an employee of Merck KGaA. Dawn Langdon has participated in speakers bureaus for Bayer, Merck, Almirall, Excemed, Teva, Roche, Novartis, Biogen, and Sanofi; has received consultancy honoraria from Novartis, Bayer, Merck, Biogen, Teva, and Sanofi; and has received research grants from Bayer, Merck, Novartis, and Biogen, all paid to her institution.

Compliance with Ethics Guidelines. This article does not contain any studies with human participants or animals performed by any of the authors.

Open Access. This article is distributed under the terms of the Creative Commons Attribution-NonCommercial 4.0 International License (http://creativecommons.org/licenses/ by-nc/4.0/), which permits any noncommercial use, distribution, and reproduction in any medium, provided you give appropriate credit to the original author(s) and the source, provide a link to the Creative Commons license, and indicate if changes were made.

\section{REFERENCES}

1. World Health Organization. Patient Engagement: Technical Series on Safer Primary Care 2016. http:// apps.who.int/iris/bitstream/handle/10665/252269/ 9789241511629-eng.pdf. Accessed Oct 2018.

2. Carman KL, Dardess P, Maurer M, Sofaer S, Adams K, Bechtel C, Sweeney J. Patient and family engagement: a framework for understanding the elements and developing interventions and policies. Health Aff. 2013;32(2):223-31.

3. Köpke S, Giordano A, Veronese S, Christin Rahn A, Kleiter I, Basedow-Rajwich B, Fornari A, Battaglia MA, Drulovic J, Kooij L, Koops J, Mens J, Meza Murillo ER, Milanov I, Milo R, Patti F, Pekmezovic T, Sastre-Garriga J, Vosburgh J, Voltz R, Bay J, Oliver DJ, Solari A. Patient and caregiver involvement in the formulation of guideline questions: findings from the European Academy of Neurology guideline on palliative care of people with severe multiple sclerosis. Eur J Neurol. 2018. https://doi.org/10. 1111/ene.13760.

4. National Health Service England. Shared decision making. https://www.england.nhs.uk/shareddecision-making/. Accessed Oct 2018.

5. Centre for Advancing Health (CFAH). Here to Stay: What Health Care Leaders Say About Patient Engagement. 2014. http://www.cfah.org/pdfs/here_ to_stay_2014.pdf. Accessed Oct 2018.

6. Reen GK, Silber E, Langdon DW. Interventions to support risk and benefit understanding of diseasemodifying drugs in Multiple Sclerosis patients: A systematic review. Patient Educ Couns. 2017;100(6):1031-48.

7. Reen GK, Silber E, Langdon DW. Multiple sclerosis patients' understanding and preferences for risks and benefits of disease-modifying drugs: A systematic review. J Neurol Sci. 2017;375:107-22.

8. Reen GK, Silber E, Langdon DW. Best Methods of Communicating Clinical Trial Data to Improve Understanding of Treatments for Patients with Multiple Sclerosis. Value Health. 2018;21(7):762-6.

9. Rieckmann P, Centonze D, Elovaara I, Giovannoni G, Havrdová E, Kesselring J, Kobelt G, Langdon D, Morrow SA, Oreja-Guevara C, Schippling S, Thalheim C, Thompson H, Vermersch P, Aston K, Bauer B, Demory C, Giambastiani MP, Hlavacova J, 
Nouvet-Gire J, Pepper G, Pontaga M, Rogan E, Rogalski C, van Galen P, Ben-Amor AF. Unmet needs, burden of treatment, and patient engagement in multiple sclerosis: A combined perspective from the MS in the 21st Century Steering Group. Mult Scler Relat Disord. 2018;19:153-60.

10. Rieckmann P, Boyko A, Centonze D, Elovaara I, Giovannoni G, Havrdová E, Hommes O, Kesselring J, Kobelt G, Langdon D, LeLorier J, Morrow SA, Oreja-Guevara C, Schippling S, Thalheim C, Thompson H, Vermersch P. Achieving patient engagement in multiple sclerosis: A perspective from the multiple sclerosis in the 21st Century Steering Group. Mult Scler Rel Disord. 2015;4(3):202-18.

11. Heesen C, Köpke S, Solari A, Geiger F, Kasper J. Patient autonomy in multiple sclerosis-possible goals and assessment strategies. J Neurol Sci. 2013;331(1-2):2-9.

12. D'Amico E, Leone C, Patti F. Disability may influence patient willingness to participate in decision making on first-line therapy in multiple sclerosis. Funct Neurol. 2016;31(1):21-3.

13. National Collaborating Centre for Chronic Conditions. Multiple sclerosis: National clinical guideline for diagnosis and management in primary and secondary care. London: Royal College of Physicians (UK); 2004.

14. Rosenbaum L. The Paternalism Preference-Choosing Unshared Decision Making. N Engl J Med. 2015;373(7):589-92.

15. Chase D. Patient engagement is the blockbuster drug of the century. Forbes. 9th September 2012. https://www.forbes.com/sites/davechase/2012/09/ 09/patient-engagement-is-the-blockbuster-drug-ofthe-century/\#270979295638. Accessed Oct 2018.

16. Department of Health. Creating a patient-led NHS Delivering the NHS improvement plan. 2005. http://webarchive.nationalarchives.gov.uk/201301 07105354/http://www.dh.gov.uk/prod_consum_dh/ groups/dh_digitalassets/@dh/@en/documents/digital asset/dh_4106507.pdf. Accessed Oct 2018.

17. Aljumah M, Alroughani R, Alsharoqi I, Bohlega SA, Dahdaleh M, Deleu D, Esmat K, Khalifa A, Sahraian MA, Szólics M, Altahan A, Yamout BI, Rieckmann P, Daif A. Future of management of multiple sclerosis in the Middle East: a consensus view from specialists in ten countries. Mult Scler Int. 2013;2013:952321.

18. Institute of Medicine. Crossing the Quality Chasm: A New Health System for the 21st Century 2001. http://www.nap.edu/openbook.php?record_id=100 27\&page $=23$. Accessed Oct 2018.
19. Institute of Medicine. Best care at lower cost: the path to continuously learning health care in America 2012. https://www.nap.edu/download/ 13444\#. Accessed Oct 2018.

20. Chow S, Teare G, Basky G. Shared decision making: helping the system and patients make quality health care decisions. Health Quality Council, Saskatoon (2009). https://hqc.sk.ca/Portals/0/docu ments/Shared_Decision_Making_Report_April_08_ 2010.pdf. Accessed Oct 2018.

21. Meterko M, Wright S, Lin H, Lowy E, Cleary PD. Mortality among patients with acute myocardial infarction: the influences of patient-centered care and evidence-based medicine. Health Serv Res. 2010;45:1188-204.

22. Burks J, Marshall TS, Ye X. Adherence to diseasemodifying therapies and its impact on relapse, health resource utilization, and costs among patients with multiple sclerosis. Clinicoecon Outcomes Res. 2017;9:251-60.

23. Evans C, Marrie RA, Zhu F, Leung S, Lu X, Melesse DY, Kingwell E, Zhao Y, Tremlett H. Adherence and persistence to drug therapies for multiple sclerosis: A population-based study. Mult Scler Relat Disord. 2016;8:78-85.

24. Yermakov S, Davis M, Calnan M, Fay M, Cox-Buckley B, Sarda S, Duh MS, Iyer R. Impact of increasing adherence to disease-modifying therapies on healthcare resource utilization and direct medical and indirect work loss costs for patients with multiple sclerosis. J Med Econ. 2015;18(9):711-20.

25. Bergvall N, Makin C, Lahoz R, Agashivala N, Pradhan A, Capkun G, Petrilla AA, Karkare SU, McGuiness $\mathrm{CB}$, Korn JR. Relapse rates in patients with multiple sclerosis switching from interferon to fingolimod or glatiramer acetate: a US claims database study. PLoS One. 2014;9(2):e88472.

26. Lugaresi A, Ziemssen T, Oreja-Guevara C, Thomas D, Verdun E. Improving patient-physician dialog: commentary on the results of the MS Choices survey. Patient Prefer Adherence. 2012;6:143-52.

27. Colligan E, Metzler A, Tiryaki E. Shared decisionmaking in multiple sclerosis. Mult Scler J. 2017;23(2):185-90.

28. Glusman M, Bruce A, Thelen J, Smith J, Lynch S, Catley D, Bennett KK, Bruce J. Discontinuing Treatment Against Medical Advice: The Role of Perceived Autonomy Support From Providers in Relapsing-Remitting Multiple Sclerosis. Ann Behav Med. 2018. https://doi.org/10.1093/abm/kay035

29. Lavorgna L, Lanzillo R, Brescia Morra V, Abbadessa G, Tedeschi G, Bonavita S. Social Media and 
Multiple Sclerosis in the Posttruth Age. Interact J Med Res. 2017;6(2):e18.

30. de Seze J, Borgel F, Brudon F. Patient perceptions of multiple sclerosis and its treatment. Patient Prefer Adherence. 2012;6:263-73.

31. Köpke S, Solari A, Rahn A, Khan F, Heesen C, Giordano A. Information provision for people with multiple sclerosis. Cochrane Database Syst Rev. 2018;10:CD008757.

32. Ceuninck van Capelle A, Meide HV. Vosman FJH, Visser LH. A qualitative study assessing patient perspectives in the process of decision-making on disease modifying therapies (DMT's) in multiple sclerosis (MS). PLoS One. 2017;12(8):e0182806.

33. Tintoré $\mathrm{M}$, Alexander $\mathrm{M}$, Costello $\mathrm{K}$, Duddy $\mathrm{M}$, Jones DE, Law N, O'Neill G, Uccelli A, Weissert R, Wray S. The state of multiple sclerosis: current insight into the patient/health care provider relationship, treatment challenges, and satisfaction. Patient Prefer Adherence. 2017;11:33-45.

34. Ha JF, Longnecker N. Doctor-patient communication: a review. Ochsner J. 2010;10(1):38-43.

35. Pietrolongo E, Giordano A, Kleinefeld M, Confalonieri P, Lugaresi A, Tortorella C, Pugliatti M, Radice D, Goss C, Heesen C, Solari A. AutoMS group. Decision-making in multiple sclerosis consultations in Italy: third observer and patient assessments. PloS One. 2013;2013(8):e60721.

36. Kasper J, Köpke S, Mühlhauser I, Nübling M, Heesen C. Informed shared decision making about immunotherapy for patients with multiple sclerosis (ISDIMS): a randomized controlled trial. Eur J Neurol. 2008;15:1345-52.

37. Kasper J, Heesen C, Köpke S, Fulcher G, Geiger F. Patients and observers perceptions of involvement differ. Validation study on inter-relating measures for shared decision making. PLoS One. 2011;2011(6):e26255.

38. Marvel MK, Epstein RM, Flowers K, Beckman HB. Soliciting the Patient's Agenda: Have We Improved? JAMA. 1999;281(3):283-7.
39. Langewitz W, Denz M, Keller A, Kiss A, Rüttimann S, Wössmer B. Spontaneous talking time at start of consultation in outpatient clinic: cohort study. BMJ. 2002;325(7366):682-3.

40. Rieckmann P. Comparing patient and healthcare professional perceptions on multiple sclerosis management and care - where do their priorities differ? Results from a qualitative survey. ECTRIMS Online Library. 2017;200469.

41. Rothwell PM, McDowell Z, Wong CK, Dorman PJ. Doctors and patients don't agree: cross sectional study of patients' and doctors' perceptions and assessments of disability in multiple sclerosis. BMJ. 1997;314(7094):1580-3.

42. Heesen C, Haase R, Melzig S, Poettgen J, Berghoff M, Paul F, Zettl U, Marziniak M, Angstwurm K, Kern $\mathrm{R}$, Ziemssen T, Stellmann JP. Perceptions on the value of bodily functions in multiple sclerosis. Acta Neurol Scand. 2018;137(3):356-62.

43. Kremenchutzky M, Walt L. Perceptions of health status in multiple sclerosis patients and their doctors. Can J Neurol Sci. 2013;40(2):210-8.

44. Ysrraelit MC, Fiol MP, Gaitán MI, Correale J. Quality of Life Assessment in Multiple Sclerosis: Different Perception between Patients and Neurologists. Front Neurol. 2018;8:729.

45. van der Linden FA, D'hooghe MB, Nagels G, Van Nunen A, Polman CH, Uitdehaag BM. Proxy ratings from multiple sources: disagreement on the impact of multiple sclerosis on daily life. Eur J Neurol. 2008;15(9):933-9.

46. Heesen C, Köpke S, Richter T, Kasper J. Shared decision making and self-management in multiple sclerosis-a consequence of evidence. J Neurol. 2007;254(S2):II116-21.

47. Levinson W, Roter DL, Mullooly JP, Dull VT, Frankel RM. Physician-patient communication. The relationship with malpractice claims among primary care physicians and surgeons. JAMA. 1997;277(7):553-9. 